\title{
FGF/FGFR2 Protects against Tubular Cell Death and Acute Kidney Injury Involving Erk1/2 Signaling Activation
}

\author{
Zhuo Xu ${ }^{a}$ Xingwen Zhu ${ }^{b}$ Mingjie Wang ${ }^{a}$ Yibing Lu ${ }^{b}$ Chunsun Dai ${ }^{a}$ \\ ${ }^{a}$ Center for Kidney Disease, the Second Affiliated Hospital, Nanjing Medical University, Nanjing, China; ${ }^{\text {b }}$ Endocrine \\ Department, the Second Affiliated Hospital, Nanjing Medical University, Nanjing, China
}

\section{Keywords}

Acute kidney injury · Kidney · Kidney disease - Tubular cells · FGFR2

\begin{abstract}
Background: Fibroblast growth factors (FGFs) are heparinbinding proteins involved in a variety of biological processes, and part of them may act through binding with cell membrane receptor FGFR2. Objectives: To clarify the role and mechanisms of FGFR2 signaling in tubular cell survival and acute kidney injury (AKI). Method: In this study, kidney ischemia/reperfusion (IR) or cisplatin injection was used to induce AKI in mice. Results: In the kidneys after IR or cisplatin injection, the expression of FGFs and Erk1/2 phosphorylation were elevated. To investigate the role of FGFs in tubular cell survival and AKI, a mouse model with tubular cell specific FGFR2 gene disruption was generated. The knockouts were born normal. At 2 months of age, about one-third of the knockouts developed mild hydronephrosis. Ablation of FGFR2 in tubular cells aggravated acute kidney dysfunction
\end{abstract}

Zhuo Xu, Xingwen Zhu and Mingjie Wang contributed equally to this work.

karger@karger.com www.karger.com/kdd

Karger!

\section{(C) 2020 The Author(s)}

Published by S. Karger AG, Basel

Karger

Open access

This article is licensed under the Creative Commons AttributionNonCommercial-NoDerivatives 4.0 International License (CC BYNC-ND) (http://www.karger.com/Services/OpenAccessLicense). Usage and distribution for commercial purposes as well as any distribution of modified material requires written permission. as well as tubular cell apoptosis induced by IR or cisplatin. In addition, Erk1/2 phosphorylation was less in the knockout kidneys than in control littermates at day 1 after cisplatin injection. In cultured NRK-52E cells, recombinant FGF2 protein induced Erk1/2 phosphorylation and inhibited cisplatin-induced cell death. PD98059 abolished Erk1/2 phosphorylation and partly reversed the protective effect of FGF2 on cisplatin-induced cell death. Conclusions: This study indicates that FGF/FGFR2 signaling plays an important role in protecting against tubular cell death and AKI, which is partly through stimulating Erk $1 / 2$ activation.

(c) 2020 The Author(s)

Published by S. Karger AG, Basel

\section{Introduction}

Acute kidney injury (AKI), manifested as a rapid decline of renal function within hours to days, is a common and devastating disease in critical care unit patients. Although tremendous efforts have been made, the shortterm mortality for the AKI patients remains extremely
Yibing Lu, MD

Endocrine Department, 2nd Affiliated Hospital

Nanjing Medical University, 262 North Zhongshan Road

Nanjing, Jiangsu 210003 (China)

luyibing2004@126.com

Chunsun Dai, MD, PhD

Center for Kidney Disease, 2nd Affiliated Hospital

Nanjing Medical University, 262 North Zhongshan Road

Nanjing, Jiangsu 210003 (China)

daichunsun@njmu.edu.cn 
high, and some patients who survived AKI may develop chronic kidney disease in the end [1-3]. It has been well demonstrated that many pathological processes are involved in the initiation and progression of AKI, including endothelial and epithelial cell death, tubular lumen obstruction, as well as inflammation $[4,5]$. Among of them, tubular cell death plays an essential role in renal dysfunction and AKI [6-9].

Fibroblast growth factors (FGFs) are a group of heparin-binding proteins involved in many biological processes, such as embryonic development, tumorigenesis, cell proliferation, differentiation, as well as cell survival [10]. The role and mechanisms of FGFs in kidney development and disease are very complicated. As previously reported, FGF2 may protect cultured rat metanephric mesenchymal (MM) cells from apoptosis. Mice null for FGF7 or FGF10 have smaller kidneys, but with normal appearance of nephron, while conditional deletion of FGF8 from MM interrupts nephron formation in mice [11-13]. In adult rats, long-term treatment of FGF2 may result in focal segmental glomerulosclerosis [14, 15]. Hoffman et al. reported that FGF2 is increased in the urine from neonates with AKI, suggesting a potential involvement of FGF2 in AKI [16]. In LPS-induced AKI in mice, FGF2 treatment had a protective effect [16]. In contrast, FGF1 may disturb kidney repair after ischemia/reperfusion (IR) [17].

At least four types of FGF receptors (FGFRs) have been identified in both developing and mature mammalian kidneys. The function of FGFRs is regulated by its FGF ligands through the variety of ligand binding affinity and specificity [13]. In most of the cell types, binding of FGFs with FGFRs may activate intracellular signaling pathways including MAP kinase, PI3k/AKT and phospholipase $\mathrm{C} \gamma$ $[10,18]$. Although four types of FGFR can be detected in the embryonic kidneys, previous studies showed that only FGFR1 and FGFR2 are indispensable for nephron development. FGFR1 expression is dominant in MM lineages $[19,20]$, whereas FGFR2 is mainly located in Wolffian duct, ureteric bud (UB) tree, and the differentiating nephron (beginning with vesicle) $[19,21]$. Transgenic and conditional knockout approaches in whole animals have shown that FGFR1 and FGFR2 in kidney mesenchyme are critical for early MM and UB formation. Loss of FGFR2 in the MM leads to kidney and urinary tract anomalies such as vesico-ureteral reflux [13, 22-24]. It seems that FGFR signaling is critical for patterning of virtually all renal lineages at early and later stages of development. Dr. Bates found that concurrently deleting FGFR1 and FGFR2 in MM results in small kidneys, fewer nephron as well as unbranched UB. Much more cell apoptosis is present in the mutant mesenchyme dorsal and the UB in the knockout mice [22]. Although many lines of evidence have documented the critical role of FGFs/FGFRs in kidney development, the role and mechanisms of FGFR in AKI remain largely unknown.

In this study, we found that the members of FGFs were upregulated in tubular cells with IR or cisplatin-induced AKI in mice. Mice with tubular cell-specific deletion of FGFR2 were born normal but susceptible to cisplatin or IR induced AKI. In cultured NRK-52E cells, recombinant FGF2 protein could activate Erk1/2 signaling and protect against cisplatin-induced cell death. Blockade of Erk1/2 signaling could partially antagonize FGF2-promoted cell survival. These findings suggest that FGFR2 protects against tubular cell death and AKI partially through the Erk1/2 signaling pathway.

\section{Materials and Methods}

\section{Mice and Animal Model}

The FGFR2-floxed mice and Ksp-Cre transgenic mice were purchased from Jackson lab [25]. By mating the FGFR2-floxed mice with Ksp-Cre mice, mice heterozygous for the FGFR2-floxed alleles (genotype: FGFR2 $2^{\mathrm{fl} / \mathrm{wt}}, \mathrm{Cre}^{+/-}$) were generated. In order to inactivate both FGFR alleles, these mice were crossbred. Then, we obtained the conditional knockout mice in which the FGFR2 gene was specifically disrupted in renal tubular epithelial cells (genotype: FGFR $\left.{ }^{\mathrm{fl} / \mathrm{fl}}, \mathrm{Cre}^{+/-}\right)$. The breeding protocol also generated heterozygous littermates (genotype: FGFR2 $2^{\mathrm{fl} / \mathrm{wt}}, \mathrm{Cre}^{+/-}$), and wild type and several groups with different genotypes (FGFR $2^{\mathrm{fl} / \mathrm{fl}}, \mathrm{Cre}^{-/-}$, or $\left.\mathrm{FGFR}^{\mathrm{fl} / \mathrm{wt}}, \mathrm{Cre}^{-/-}\right)$. Transgenic litters were identified using a PCR reaction from DNA isolated from tail specimen at 3 weeks after birth. The primers used for genotyping were as follows: Cre: sense: $5^{\prime}$-GCAGATCTGGCTCTCCAAAG-3' and anti-sense: $5^{\prime}$-AGGCAAATTTTGGTGTACGG-3'; FGFR2: sense: $5^{\prime}$-TTCCTGTTCGACTATAGGAGCAACAGGCGG-3' ${ }^{\prime}$ and anti-sense: $5^{\prime}$-GAGAGCAGGGTGCAAGAGGCGACCAGTCAG-3'. The same gender littermates with genotypes (FGFR2 $2^{\mathrm{fl} / \mathrm{fl}}, \mathrm{Cre}^{-/-}$) were used as control through the experiment.

Male CD-1 mice weighing 18-22 g were acquired from the Animal Center of Nanjing Medical University. Male CD-1 mice, tubule-FGFR2 ${ }^{-1-}$ mice, or their control littermates were anesthetized by $5 \%$ chloral hydrate at the dosage of $0.1 \mathrm{~mL} / 10 \mathrm{~g}$ body weight. By exposure of the kidneys through a midline incision, the right renal pedicle was clamped for $40 \mathrm{~min}$. Mice were kept in the incubator at a temperature of $38^{\circ} \mathrm{C}$, and the abdominal cavity was hydrated with saline-moistened gauze. Following clamp removal, the kidney was visually assessed for reperfusion within $1 \mathrm{~min}$. Then, the left kidney was ablated. Groups of control mice were prepared as above, without clamping of the right renal pedicle or ablation of the left kidney. Groups of sham mice were only removed with the left kidney. After surgery, the animals were returned to their cages and allowed free access to food and water. Mice were sacrificed at $1,2,4,7$ days after reperfusion. Blood samples were collected for 
determining BUN and serum creatinine. Kidney tissues were harvested and snap-frozen in liquid nitrogen, then stored at $-80^{\circ} \mathrm{C}$ for extraction of RNA and protein.

Male CD-1 mice, Tubule-FGFR2 ${ }^{-/-}$mice, and their control littermates received single intraperitoneal cisplatin injection at a dose of $25 \mathrm{mg} / \mathrm{kg}$ body weight. Animals were sacrificed on days 1 , 2 , and 3 after injection. Blood samples were collected for determining BUN and creatinine. Kidney tissues were harvested and snapfrozen in liquid nitrogen, then stored at $-80^{\circ} \mathrm{C}$ for extraction of RNA and protein. For histological evaluation, kidneys were fixed in $10 \%$ phosphate-buffered formalin followed by paraffin embedding.

\section{Cell Culture and Treatment}

Rat kidney tubular epithelial cells (NRK-52E) were obtained from ATCC (CRL-1571TM, Manassas, VA, USA). NRK-52E cells were cultured in DMEM/F12 medium supplemented with $10 \% \mathrm{fe}$ tal bovine serum (Invitrogen, Grand Island, NY, USA) at $37^{\circ} \mathrm{C}$. Before treatment, the cells were starved with serum-free medium for at least $12 \mathrm{~h}$. Cells were treated with FGF2 for different times. Cisplatin at a concentration of $25 \mu \mathrm{g} / \mathrm{mL}$ was used to induce apoptosis in NRK-52E cells. PD98059 (Mek1 inhibitor, Cat: P215) and cisplatin (Cat: 479306) were purchased from Sigma-Aldrich, and the FGF2 (Cat: 3139-FB) was purchased from R\&D Systems.

Urinary Albumin, Creatinine, Lysozyme, and

$N$-Acetyl- $\beta$-D-Glucosaminidase Assay

Urinary albumin concentration was measured by using a mouse Albumin ELISA Quantification kit (Bethyl Laboratories, Montgomery, TX, USA). Urinary creatinine was determined by using a creatinine Assay kit (DICT-500; BioAssay System, Hayward, CA, USA). Urinary $\mathrm{N}$-acetyl- $\beta$-D-glucosaminidase (NAG) was detected by using the NAG assay kit (Nanjing Jiancheng Bioengineering, Nanjing, China). Urinary lysozyme was detected by using Micrococcus luteus as its substrate. Briefly, $20 \mu \mathrm{L}$ of urine or $\mathrm{ddH}_{2} \mathrm{O}$ was incubated at $37^{\circ} \mathrm{C}$ for 3 min with $200 \mu \mathrm{L}$ of the substrate solution at a concentration of $100 \mu \mathrm{g} / \mathrm{mL}$ at $\mathrm{pH} 6.4$; then, the absorbance was read at $450 \mathrm{~nm}$, and the lysozyme in urine $(\mathrm{mg} / \mathrm{dL})$ was calculated.

\section{Detection of Serum BUN and Creatinine}

Serum BUN and creatinine levels were measured using a mouse BUN ELISA Quantification kit (Cat: DIUR-500, BioAssay System) and creatinine assay kit (mentioned above), respectively, according to the manufacturer's protocol.

\section{RNA Extraction and Real-Time Quantitative RT-PCR}

Total RNA isolation was extracted with Trizol Reagent (Invitrogen, Carlsbad, CA, USA) according to the manufacturer's instruction. The first-strand cDNA synthesis was using $1 \mu \mathrm{g}$ of RNA with Reverse Transcription System kit (Vazyme, Nanjing, China), following the instructions of the manufacturer. Quantitative RTPCR was performed with $2 \times$ SYBR Green PCR Master Mix Reagents (Roche, Germany), $1 \mu \mathrm{L}$ of cDNA, and specific primer pairs in the 7300 real-time PCR system (Applied Biosystems, Foster City, CA, USA). Quantitative RT-PCR reaction was carried out using standard conditions including a single denaturation cycle at $95^{\circ} \mathrm{C}$ for $3 \mathrm{~min}$, an amplification protocol of 40 cycles of denaturation at $95^{\circ} \mathrm{C}$ for $15 \mathrm{~s}$, and annealing and extension at $60^{\circ} \mathrm{C}$ for $60 \mathrm{~s}$. A postamplification melt-curve analysis was run to assess the efficiency of primer pairs. The relative levels of FGF family mRNA were calculated using the $2^{(-\Delta \Delta \mathrm{Ct})}$ method.

\section{Western Blot Analysis}

Cultured NRK-52E cells were lysed in $1 \times$ SDS sample buffer. Proteins from kidney tissue were extracted in RIPA buffer containing $1 \times \mathrm{PBS}, 1 \% \mathrm{NP}-40,0.1 \%$ SDS, $0.1 \%$ sodium deoxycholate, $1 \mu \mathrm{M}$ sodium orthovanadate, $100 \mathrm{nM}$ PMSF, $1 \%$ protease inhibitor cocktail (Cat: P8340, Sigma-Aldrich, St. Louis, MO, USA), and 1\% phosphatase II and III inhibitor cocktail (Cat: P5726 and P0044, respectively, Sigma-Aldrich) on ice. The supernatants were collected after centrifugation at $16,000 \mathrm{~g}$ for $30 \mathrm{~min}$ at $4{ }^{\circ} \mathrm{C}$. Protein levels were measured using the BCA assay (Pierce), and equal amount of protein $(50-100 \mu \mathrm{g})$ was separated on $8-12 \%$ tris-glycine polyacrylamide gels. Then, after being transferred onto nitrocellulose membranes, the target proteins were detected by using specific primary antibodies. The primary antibodies used were as follows: anti-FGF2 (Cat: ab-72316, Abcam, Cambridge, UK), anti-FGF7 (Cat: sc-1366, Santa Cruz Biotechnology, Santa Cruz, CA, USA), anti-FGF10 (Cat: sc-7917, Santa Cruz Biotechnology), anti-p-ERK1/2 (Thr202/ Tyr204) (Cat: 4370, Cell Signaling Technology, Beverly, MA, USA), anti-ERK1/2 (Cat: 4695, Cell Signaling Technology), anti-phospho-Bad (Ser112) antibody (Cat: 9291, Cell Signaling Technology), anti-FGFR2 (Cat: sc-122, Santa Cruz Biotechnology), anti-GAPDH (Cat: FL-335, Santa Cruz Biotechnology), and anti- $\beta$-actin (Cat: sc1616, Santa Cruz Biotechnology). Quantification was performed by measuring the intensity of the signals with the Image J software.

\section{Immunohistochemistry and Immunofluorescence Staining}

The NRE-52E cells were cultured on the coverslips. Cells were fixed with cold methanol/acetone $(1: 1)$ for $10 \mathrm{~min}$ at $-20^{\circ} \mathrm{C}$. The coverslips were blocked with $2 \%$ BSA in $1 \times$ PBS buffer for 40 min at room temperature, incubated in primary antibodies overnight at $4{ }^{\circ} \mathrm{C}$ or for $2 \mathrm{~h}$ at room temperature, and stained with FITC or TRITC-conjugated secondary antibody sequentially. Cell coverslips were double stained with DAPI to visualize the cell nuclei.

The kidney tissues were fixed in $4 \%$ neutral formalin at room temperature and embedded in paraffin. Then the tissues were cut into 3- $\mu \mathrm{m}$-thick slices, deparaffinized in xylene, hydrated, and stained with HE and PAS. For quantitative analysis of the kidney injury, the injury scores were measured. The injury score was defined as the proportion of the damaged tubule on total tubule under a high-power field (HPF). Score 0 represents injury area less than $10 \%$, whereas $1,2,3$, and 4 represent the injury involving $10-25 \%, 25-50 \%, 50-75 \%$, and $>75 \%$ of the total kidney tubules, respectively. At least five randomly chosen HPF were evaluated for each mouse, and an average composite score was calculated. In some experiments, tissue sections were immunostained with primary antibodies against anti-cleaved caspase 3 (Cat: 9664, Cell Signaling Technology), anti-FGF7, antiFGF2, and anti-FGF10, p-Erk1/2 (mentioned above). The cell coverslips and kidney tissue sections were viewed with a Nikon Eclipse 80i Epi-fluorescence microscope equipped with a digital camera (DS-Ri1, Nikon).

\section{TUNEL Staining}

The apoptotic cell death was detected by terminal deoxynucleotidyl transferase-mediated dUTP nick-end labeling staining using Apoptosis Detection System (Promega, Madison, WI, USA), following the manufacturer's protocol. 
Statistical Analysis

The experiment data are presented as mean \pm SEM. Statistical analysis of the data was performed using SPASS 13.0 software. Comparison between groups was made using one-way ANOVA, followed by post hoc SNK or post hoc LSD. For comparison between two groups, Student's $t$ test was used, and paired $t$ test was used for group comparison. $p<0.05$ was considered statistically significant.

\section{Results}

FGF Gene Expression in Kidneys with AKI

In this study, an AKI model was induced in male CD1 mice by unilateral kidney IR or cisplatin injection. To determine FGF mRNA expression in kidneys from the sham or the AKI group, FGF mRNA abundance was quantitated by real-time qRT-PCR analysis. Of all 22 FGF members, 15 could be detected in sham kidneys. In kidneys after IR, mRNA abundance including FGF2, FGF6, FGF7, FGF10, FGF12, FGF13, and FGF22 was increased at all time points as indicated. FGF3, FGF4, FGF5, FGF6, FGF8, FGF14, FGF20, and FGF21 remained unchanged, and FGF1 expression was slightly decreased compared to those in sham kidneys (Fig. 1a). We also determined the mRNA expression of those FGFs that changed in the IR kidneys of the cisplatin-induced AKI model. Among of them, only FGF2 and FGF18 mRNAs were significantly upregulated, whereas the others were similar to the control (Fig. 1b).

We also detected the protein abundance for FGF2, FGF7, and FGF10 in the IR kidneys by Western blot assay, as their mRNA abundance was upregulated especially at day 1 and day 2. FGF2 protein abundance was significantly increased in kidneys at both day 1 and 2 after IR, while the other two members of FGF family were significantly upregulated at day 2 after IR compared to those in the sham control (Fig. 1d, e). FGF2 abundance was also markedly increased in kidneys with cisplatin-induced AKI (Fig. 1f, g). To further identify the localization of these three FGFs in the IR kidneys, immunostaining was deployed, and the results showed that FGF2, FGF7, and FGF10 were very weak in tubular cells from the sham group, but all of them were markedly induced in tubular cells within IR kidneys (Fig. 1c).

\section{FGFR Signaling Is Activated in the Kidneys with AKI}

The above data demonstrated that FGF gene expression was upregulated in the IR or cisplatin-induced AKI kidneys. Erk1/2 is a well-known intracellular FGFR signaling molecule. In kidneys with AKI, Western blotting assay showed that the abundance of phosphorylated Erk1/2 was markedly increased at day 1 and day 2 after IR, and declined thereafter (Fig. 2b). In cisplatin-induced AKI kidneys, Erk1/2 phosphorylation was induced at day 1 and day 2 after cisplatin injection (Fig. 2c). Immunohistochemical staining revealed that Erk1/2 phosphorylation was largely elevated in both IR and cisplatin-induced AKI kidneys and mainly localized in tubular cells (Fig. 2a). Together, these results demonstrated that Erk1/2 was stimulated in tubular epithelial cells during the early stage of AKI induced by IR or cisplatin.

\section{Generating the Mice with Tubule-Specific Ablation of FGFR2}

FGFR2 is a common receptor for FGF2, 7, and 10. To explore the physiological role of FGFs in tubular cells, we generated a mouse model with FGFR2 gene-specific deletion in kidney tubular cells by using the Cre-LoxP system [25]. As shown in Figure 3a, mice with tubule-specific ablation of FGFR2 were designated as Tubule-FGFR2 $2^{-/-}$ (genotype: FGFR2 $2^{\mathrm{fl} / \mathrm{fl}}, \mathrm{Cre}^{+/-}$, lane 1), whereas the littermates of the same gender were used as control (genotype: $\mathrm{FGFR}^{\mathrm{fl} / \mathrm{wt}}, \mathrm{Cre}^{-/-}$, or FGFR ${ }^{\mathrm{fl} / \mathrm{fl}}, \mathrm{Cre}^{-/-}$, lane 3 or 4$)$. Tubule-FGFR $2^{-1-}$ mice are viable, fertile, and with a normal lifespan.

Western blot analysis showed that FGFR2 protein level was reduced in the kidney tissue from Tubule-FGFR2 ${ }^{-/-}$mice compared to that from control littermates (Fig. 3b). Immunohistochemical staining confirmed the reduction of FGFR2 protein in kidney tubule from $\mathrm{Tu}$ bule-FGFR2 ${ }^{-1-}$ mice (Fig. 3c). There was no difference in body weight and kidney weight index at 1, 4, and 12 months after birth between two groups (Fig. 3d, e). Kidney function reflected as serum creatinine, urea, urinary NAG, urinary lysozyme, and urinary albumin level was comparable between Tubule-FGFR2 ${ }^{-1-}$ mice and the control littermates at 1 year of age (Fig. $3 \mathrm{f}-\mathrm{j}$ ). There was mild hydronephrosis in one-third of the knockouts at 2 months of age, but no obvious kidney histological change between

Fig. 1. FGF gene and protein expression in kidneys with AKI. a, b Quantitative real-time PCR analysis showing the altered expression of FGF mRNA in kidneys from mice after IR (a) and cisplatin injection (b). ${ }^{*} p<0.05$ vs. sham or vehicle control, $n=3-8$. c Representative micrographs of immunohistochemistry staining revealing increased FGF2, FGF7, and FGF10 protein expression in renal tubules after IR. $\mathbf{d}-\mathbf{g}$ Western blot and quantitative analysis demonstrating that FGF2, FGF7, and FGF10 protein expression was induced in IR kidneys (d, e) and FGF2 protein expression in mice after cisplatin injection $(\mathbf{f}, \mathbf{g}){ }^{*} p<0.05$ vs. sham or vehicle control, $n=3$.

(For figure see next page.) 

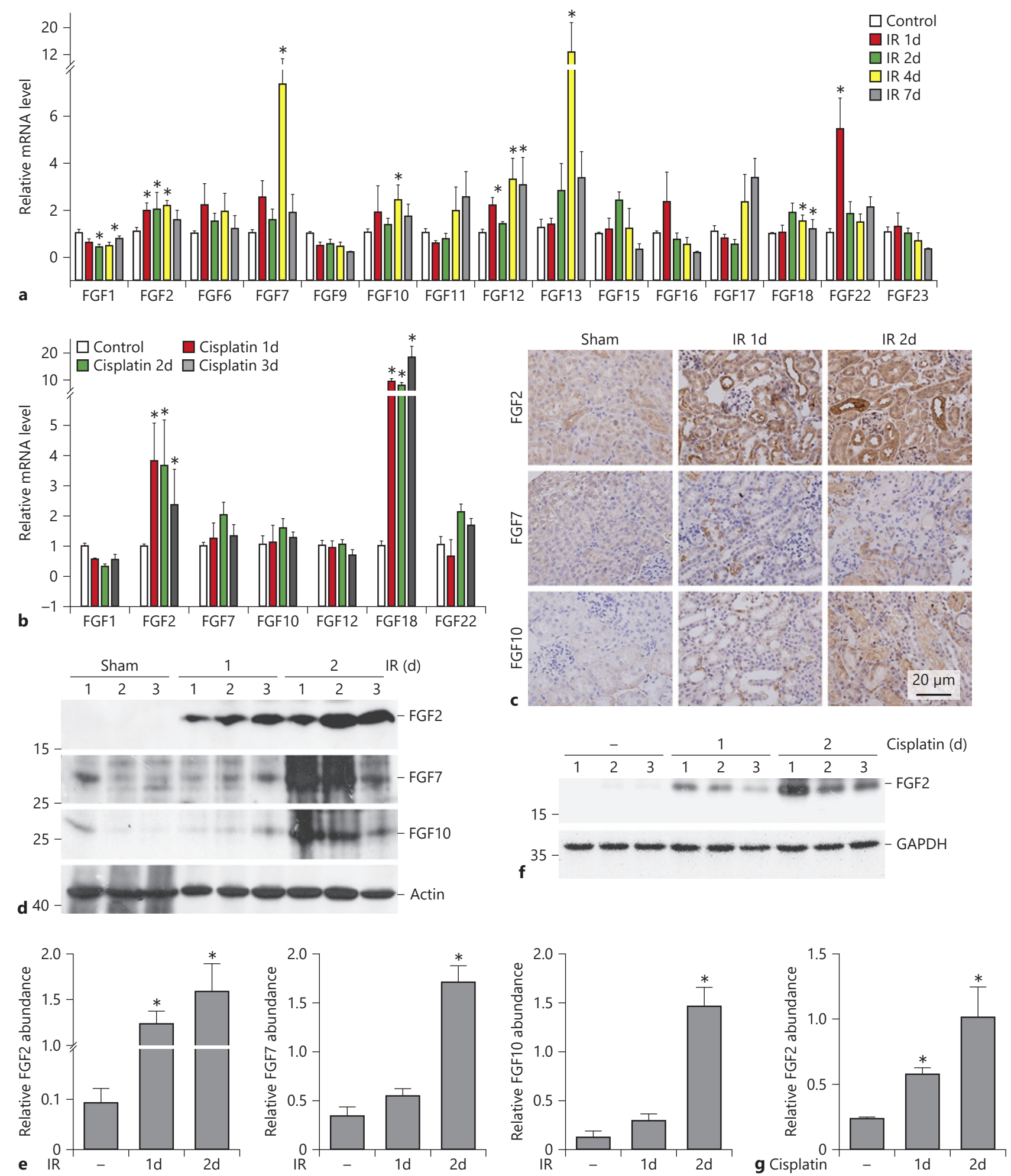
Tubule-FGFR2 ${ }^{-/-}$mice and their control littermates at 1 and 12 months after birth (Fig. 3h). Glomerular number in the kidney sections was comparable between TubuleFGFR2 ${ }^{-/}$mice and control littermates at 1 and 12 months of age (Fig. 3k).

\section{Mice with Tubule-Specific Deletion of FGFR2 Are More Susceptible to AKI}

To investigate the role of FGF/FGFR2 signaling in tubular cell survival and AKI, the mice at 2 months of age were operated with IR or injected with cisplatin to induce AKI. Figure $4 \mathrm{a}$ showed that serum creatinine and urea were significantly increased at day 1 and day 2 after IR. Specific deletion of FGFR2 aggravated the IR-induced acute kidney dysfunction (Fig. 4a, b). PAS staining showed that in Tubule-FGFR2 $2^{+/+}$mice, tubular injury presented as loss of brush border and tubular cell death after IR. And more severe kidney injury was presented in the knockout kidneys after IR (Fig. 4c, d). Similar to the IR model, at day 3 after cisplatin injection, the kidneys from control littermates had tubular injury, while in the knockout kidneys, the damage was worse compared to that in the control littermates (Fig. 4g, h). Together, the results indicate that specific deletion of FGFR2 worsens IR or cisplatininduced kidney injury.

\section{Ablation of FGFR2 in Tubular Cells Promotes \\ Tubular Cell Apoptosis}

Tubular epithelial cell apoptosis plays a critical role in the pathogenesis of AKI. As shown in Figure 5a and c, the number of TUNEL-staining positive tubular cells was dramatically increased in the Tubule-FGFR2 $2^{+/+}$kidneys, while more apoptotic tubular cells were found in TubuleFGFR2 $^{-/-}$kidneys after IR than in Tubule-FGFR2 ${ }^{+/+}$kid-

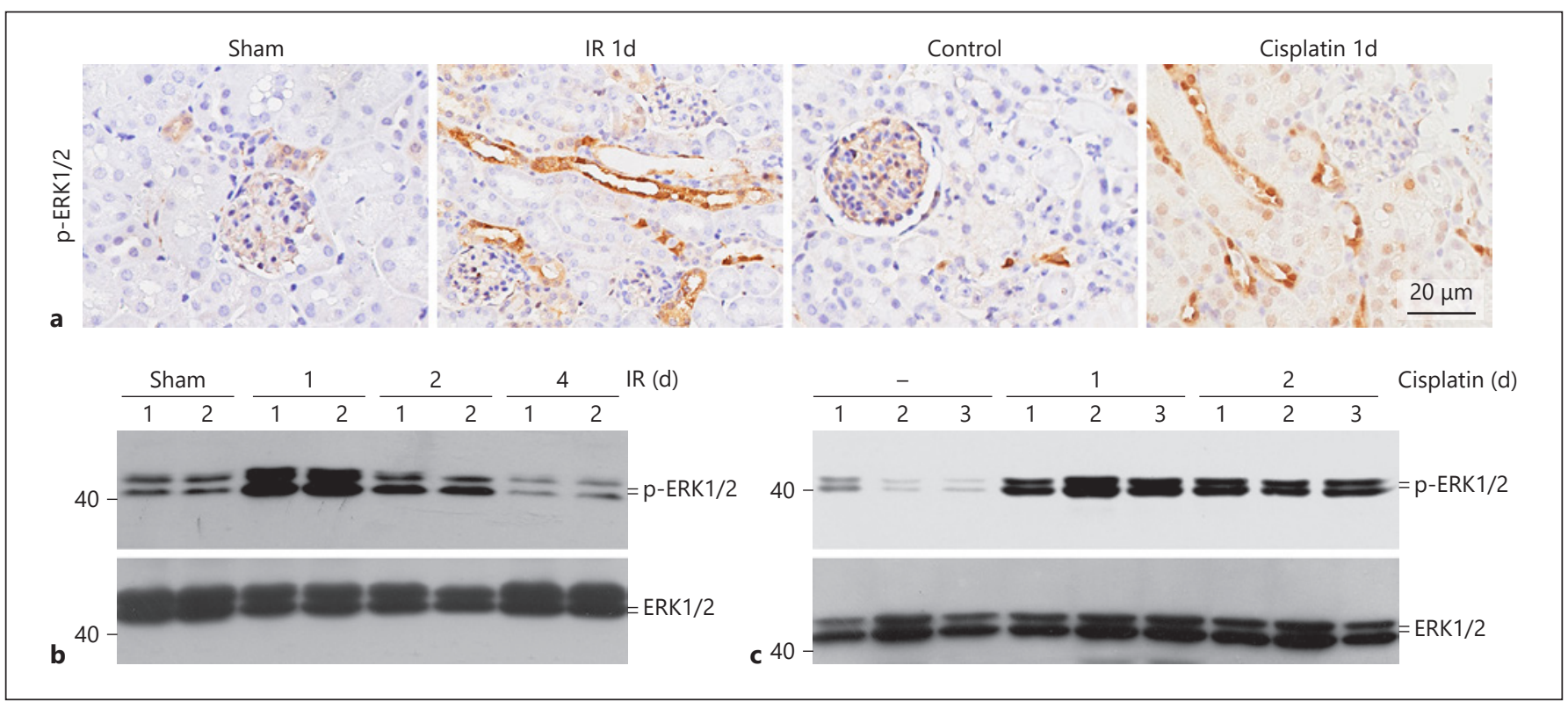

Fig. 2. Erk1/2 signaling is activated in the kidneys with AKI. a Representative immunohistochemical staining images for p-Erk1/2 in kidneys at day 1 after IR or cisplatin injection, showing the activation of Erk $1 / 2$ signaling in tubular cells. b, c Western blot analysis showing the abundance of p-Erk1/2 in kidneys at different time points after IR (b) and cisplatin injection (c). The number indicates the individual animal.

Fig. 3. Generation of mice with tubular cell-specific deletion of FGFR2. a Genotyping the mice by the PCR assay of genomic DNA. Lane 1, genotype: FGFR2 ${ }^{\mathrm{fl} / \mathrm{fl}}, \mathrm{Cre}^{+/-}$, designated as Tubule-FGFR2 ${ }^{-/-}$; lane 2, genotype: FGFR2 $2^{\mathrm{fl} / \mathrm{wt}}, \mathrm{Cre}^{+/-}$; lane 3 , genotype: FGFR2 $2^{\mathrm{fl} / \mathrm{wt}}$, $\mathrm{Cre}^{-/-}$; lane 4, genotype: FGFR2 $2^{\mathrm{fl} / \mathrm{fl}}, \mathrm{Cre}^{-/-}$; lane 4 designated as Tubule-FGFR2 ${ }^{+/+}$control. b Representative micrographs of immunohistochemical staining showing the loss of FGFR2 in kidney tubules in Tubule-FGFR2 ${ }^{-/-}$mice. c Western blot analysis showing the reduction of FGFR2 protein in the kidneys of Tubule-FGFR2 ${ }^{-1-}$ mice compared to control littermates. $\mathbf{d}-\mathbf{j}$ Mice with tubular-specific ablation of FGFR2 exhibited little difference in body weight (d), kidney weight index (e), serum BUN (f), creatinine (g), urinary NAG (h), urinary lysozyme (i), and urinary albumin (j) levels at different time points after birth, $n=3-7$. k Glomeruli were counted in TubuleFGFR2 ${ }^{-/-}$mice and control littermates at 1 and 12 months after birth, $n=3-7$. I Representative images for PAS and HE staining showing no obvious kidney histological abnormality in Tubule-FGFR2 $2^{-/-}$ mice compared to control littermates at 1 and 12 months after birth.

(For figure see next page.) 

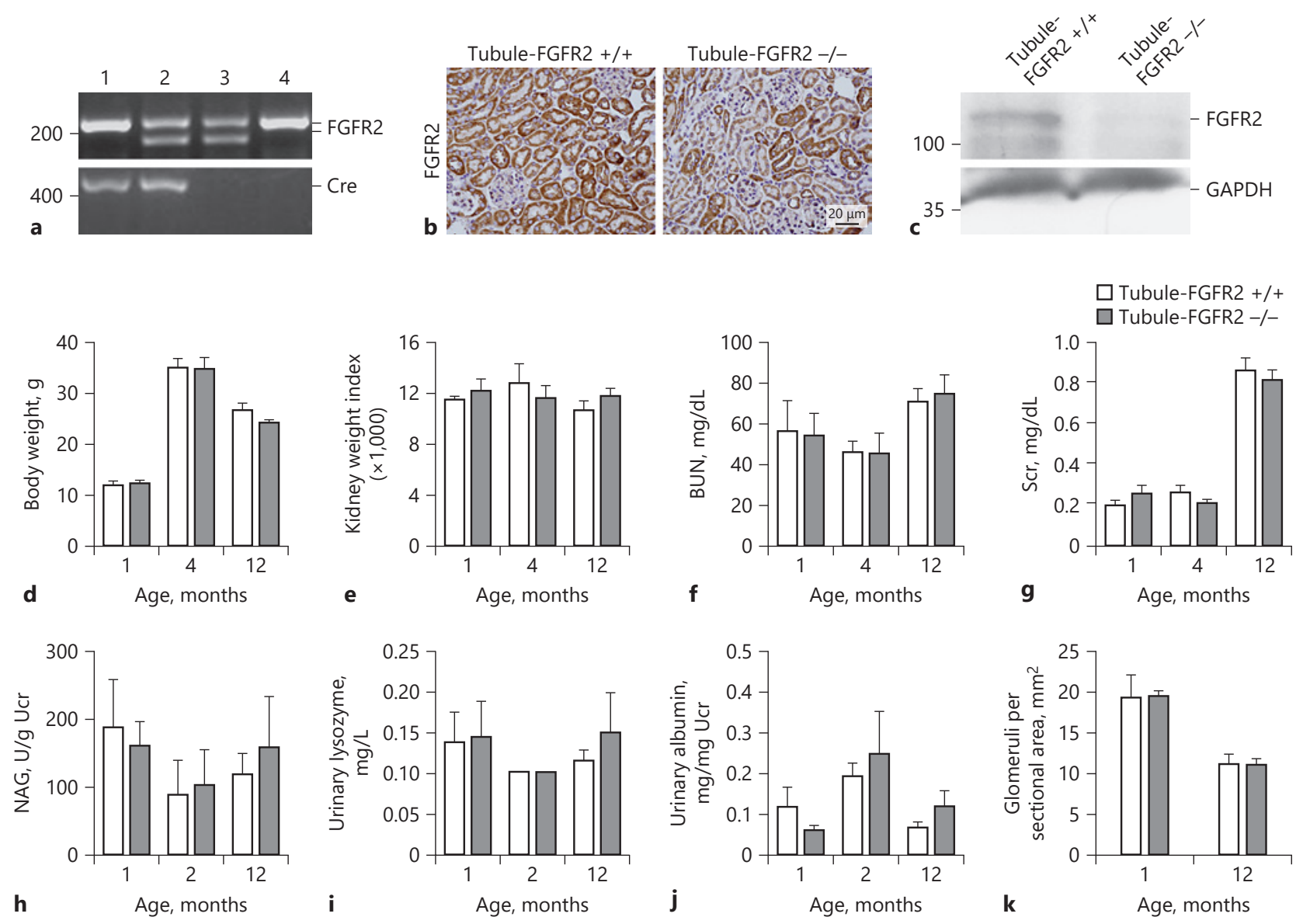

Tubule-FGFR2 +/+

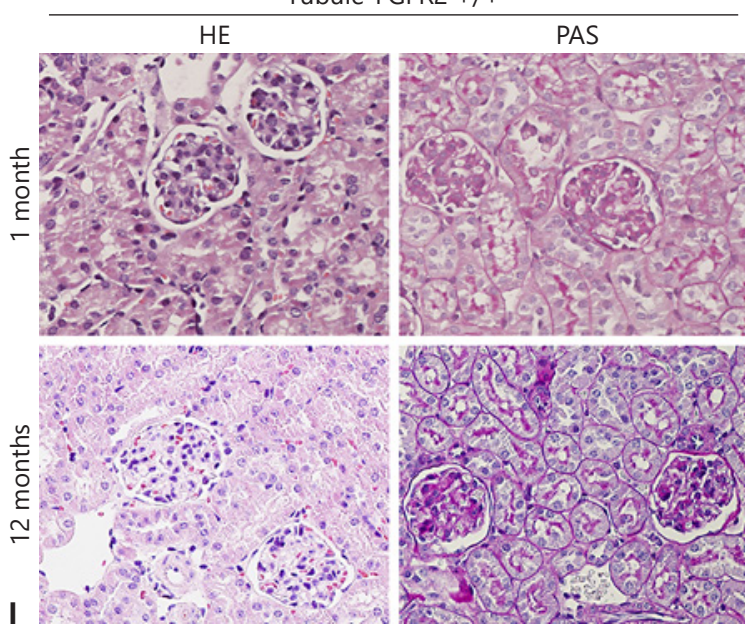

Tubule-FGFR2 -/-
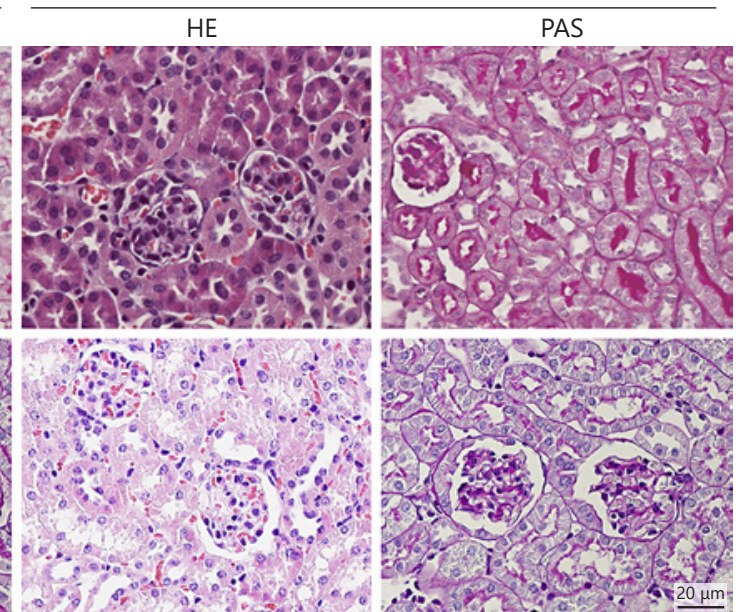

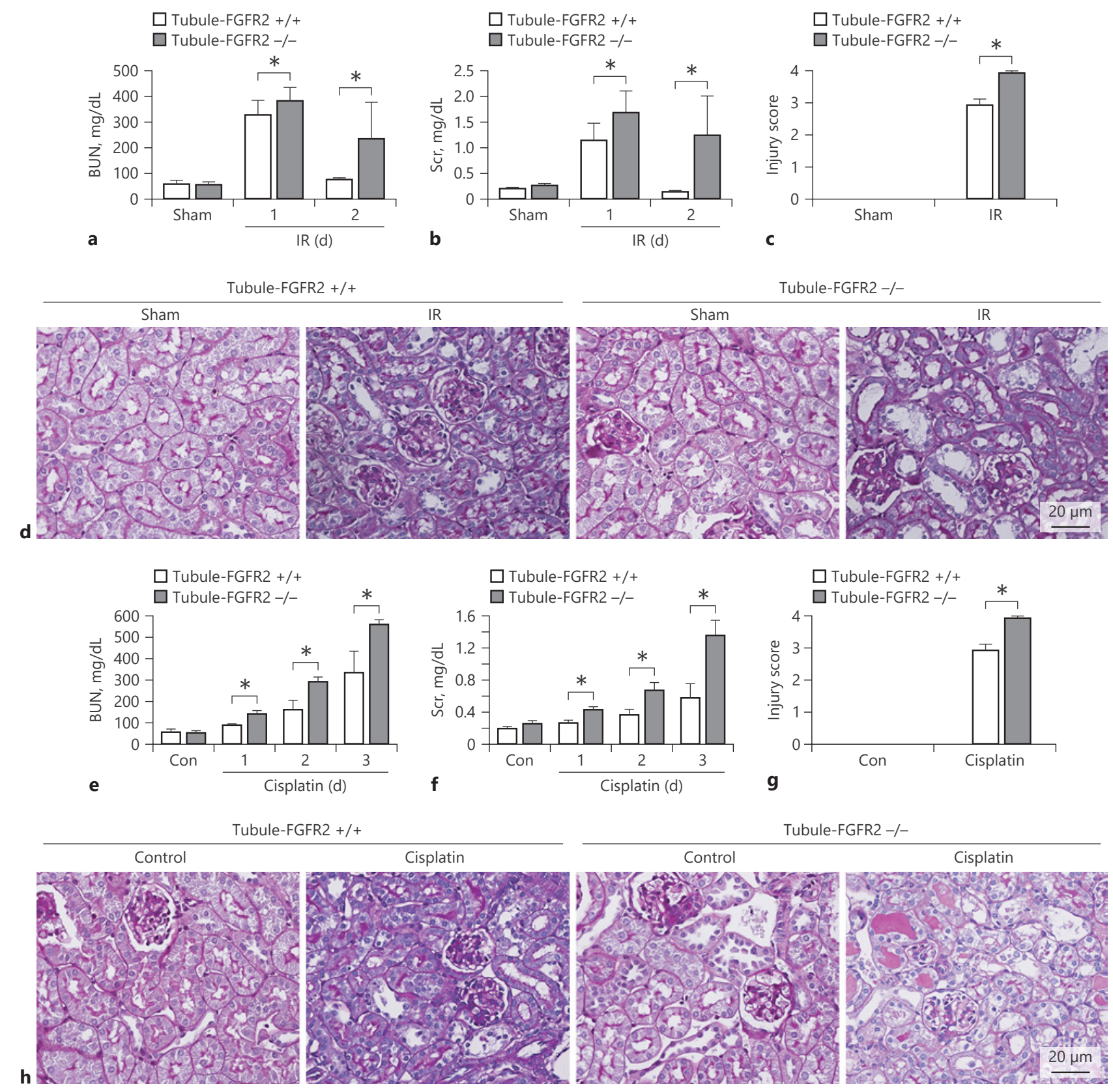

Fig. 4. Mice with tubule-specific deletion of FGFR2 are more susceptible to AKI. a, b Graphs showing serum BUN and creatinine levels in Tubule-FGFR2 ${ }^{-/-}$mice and control littermates after IR. $* p<0.05$ vs. control littermates after IR, $n=4$. c Injury scores for kidneys after IR. $* p<0.05$ vs. control littermates after IR, $n=4$. d Representative micrographs of PAS staining after IR. e, $\mathbf{f}$ Serum
BUN and creatinine levels in Tubule-FGFR2 ${ }^{-/-}$mice and control littermates increasing at different time points after cisplatin injection. ${ }^{*} p<0.05$ vs. control littermates after cisplatin injection, $n=$ 4. $\mathbf{g}$ Injury scores for the kidneys after cisplatin injection. ${ }^{*} p<0.05$ vs. control littermates, $n=4$. $\mathbf{h}$ Representative micrographs of PAS staining after cisplatin injection. 


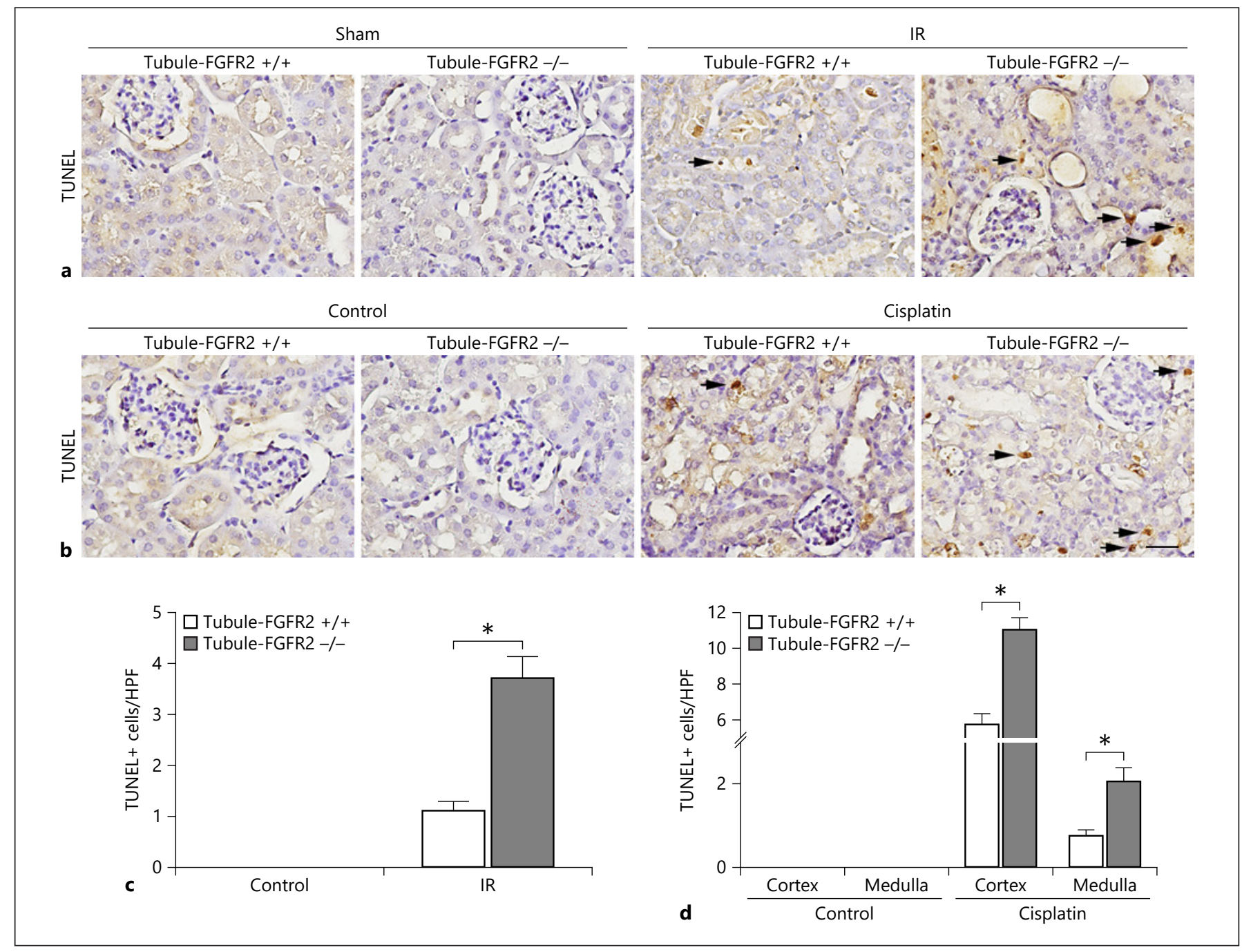

Fig. 5. Tubular cells are more susceptible to apoptosis in mice with tubule-specific ablation of FGFR2. a, b Representative micrographs showing TUNEL staining for apoptotic cells in TubuleFGFR2 $^{-1-}$ kidneys and control littermates at day 2 after IR (a) and at day 3 after cisplatin injection (b). Black arrows indicate TUNEL staining-positive cells. Scale bar, $20 \mu \mathrm{m}$. c, d Quantitative data showing the TUNEL staining-positive cells in Tubule-FGFR2-/mice and control littermates after IR (c) and cisplatin injection (d). Data are presented as TUNEL staining-positive cells per highpower field (HPF, 400 $\times$ ) in cortex and medulla. ${ }^{*} p<0.05$ vs. control littermates after IR or cisplatin injection, $n=3$.

knockout kidneys (Fig. 6a, c). Similar to the IR model, the number of cleaved caspase 3 positive-staining tubular cells was increased in control littermate kidneys after cisplatin injection, which was more significant in the knockout kidneys (Fig. 6b, d).

Erk1/2 Phosphorylation Is Diminished in the Kidneys from Tubule-FGFR2 ${ }^{-/}$Mice after Cisplatin Injection

Erk1/2 is a major downstream mediator of FGF/ FGFR2 signaling. We found that Erk1/2 was phosphorylated in the kidney tubule after cisplatin injection in mice. 


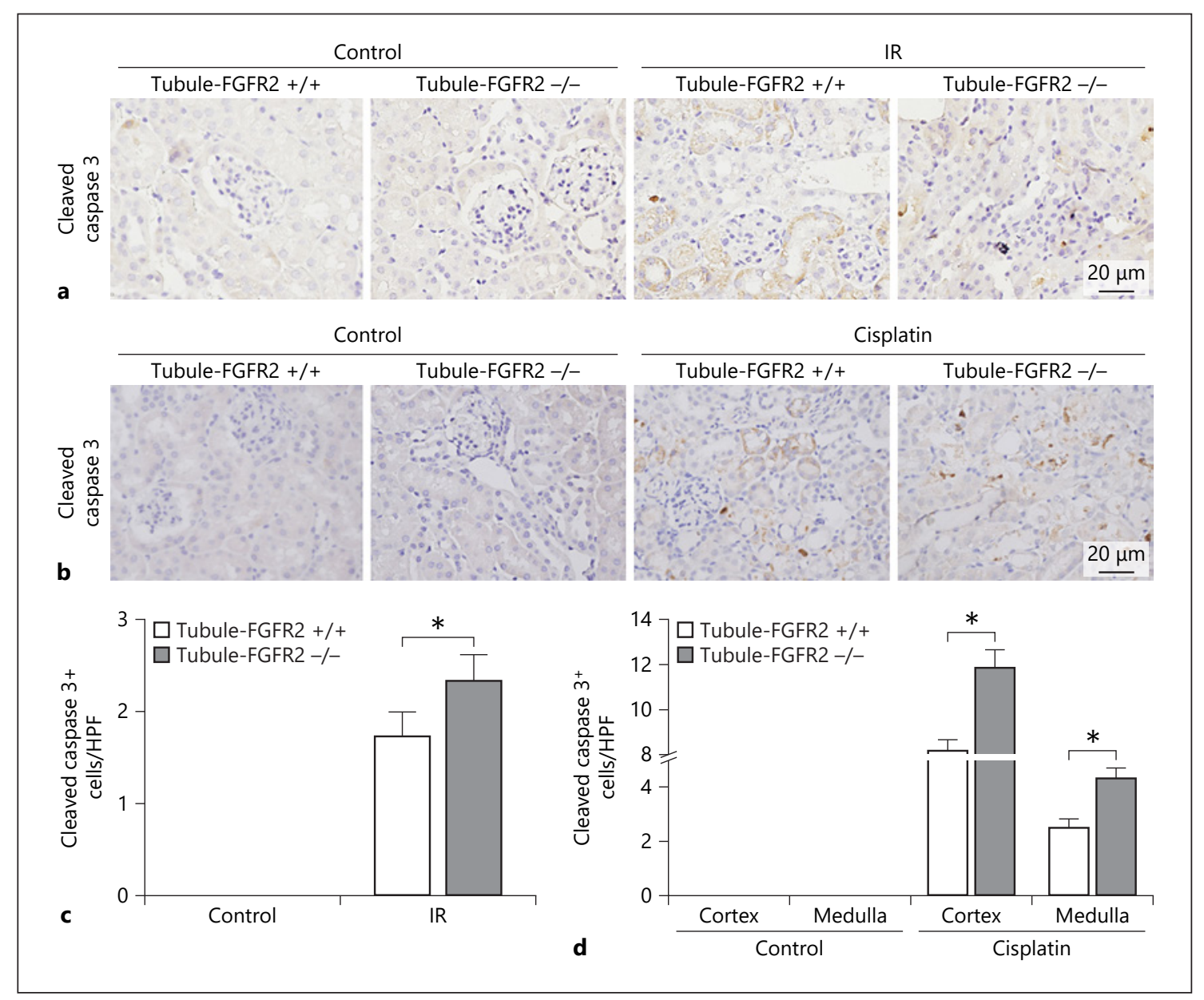

Fig. 6. Ablation of FGFR2 aggravates caspase 3 cleaved in mice after cisplatin injection. a, b Representative micrographs showing the immunohistochemical staining of cleaved caspase 3 in TubuleFGFR2 $^{-1-}$ kidneys and control littermates at day 2 after IR (a) and at day 3 after cisplatin injection (b). c, d Quantitative data showing

We then investigated whether Erk1/2 phosphorylation was decreased in the knockout kidneys compared to their control littermates after cisplatin injection. As shown in Figure $7 \mathrm{~b}$, the phosphorylation of Erk1/2 was elevated and peaked at day 1 , slightly declined at day 2 , and returned to baseline at day 3 after cisplatin injection in Tubule-FGFR2 ${ }^{+/+}$mice, while in the knockouts, the change pattern for Erk1/2 phosphorylation is different. The phosphorylated Erk1/2 was slightly elevated at day 1, continued to increase at day 2 , and declined at day 3 after cisplatin injection (Fig. 7b, c), while Erk1/2 phosphorylation increased slower and less in Tubule-FGFR2 ${ }^{-1-}$ kidneys compared to that in Tubule-FGFR2 $2^{+/+}$kidneys (Fig. 7c). Immunohistochemical staining for $\mathrm{p}$-Erk1/2 further confirmed the results of Western blot assay the cleaved caspase 3-positive cells in Tubule-FGFR2 ${ }^{-/-}$mice and control littermates after IR (c) and cisplatin injection (d). Data are presented as TUNEL staining-positive cells per high-power field (HPF, 400x) in cortex and medulla. ${ }^{*} p<0.05$ vs. control littermates after IR or cisplatin injection, $n=3$.

(Fig. 7a). These results indicate that the loss of FGFR2 may partly abolish Erk1/2 phosphorylation induced by cisplatin soon after cisplatin injection.

It has been reported that Bad may be the downstream target of Erk1/2 signaling. We detected the Bad phosphorylation in the kidney tissue at day 1 after cisplatin injection. As shown in Figure $7 \mathrm{~d}$ and e, $\mathrm{p}$-Bad abundance was significantly reduced in Tubule-FGFR2 ${ }^{-/-}$mice compared to their control littermates after cisplatin injection.

\section{FGF2 Protects against Cisplatin-Induced Cell}

Apoptosis via the Erk1/2 Pathway in NRK-52E Cells

To further investigate the role and mechanisms of FGF in tubular epithelial cell survival, we treated the NRK-52E 


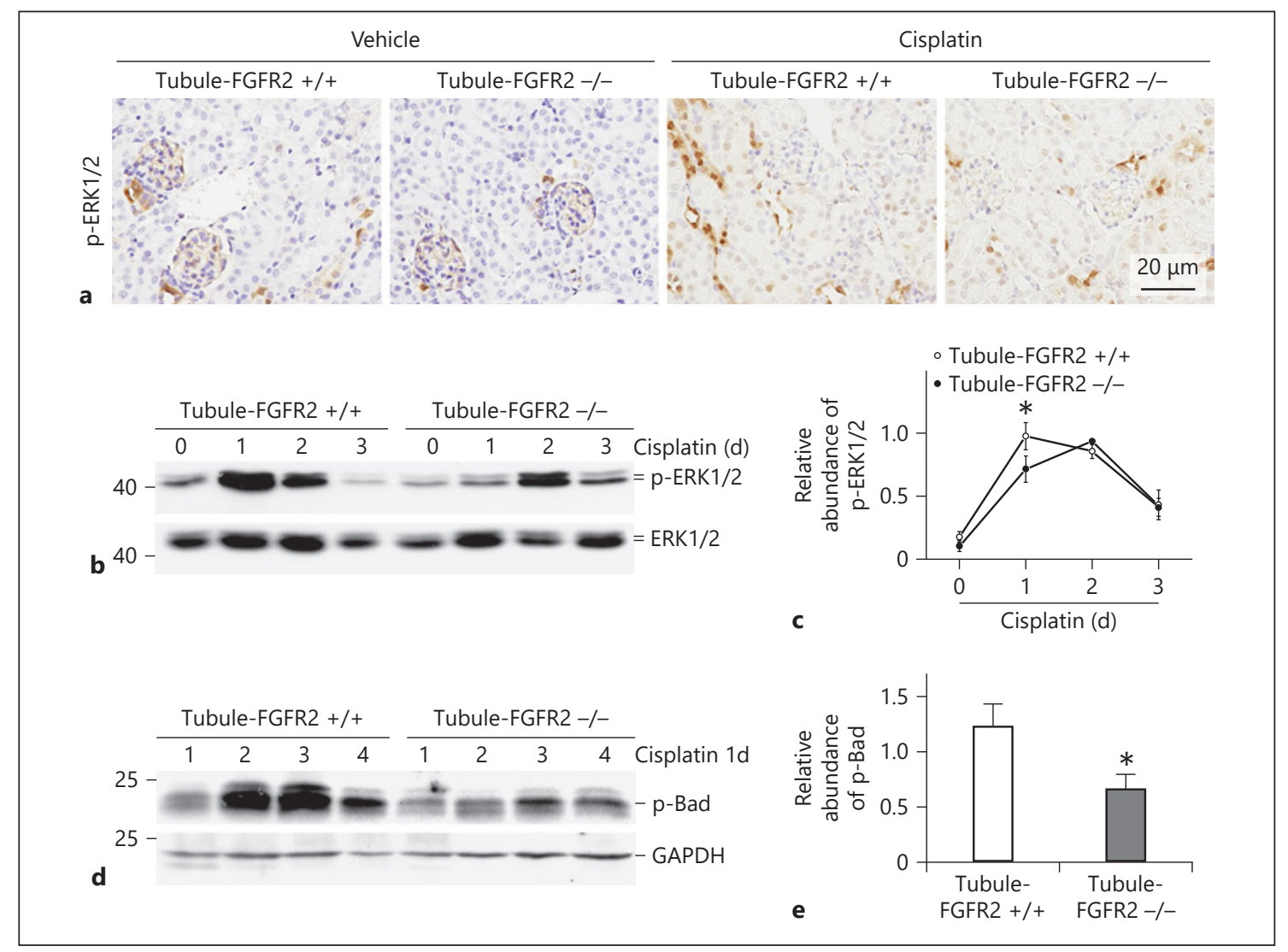

Fig. 7. Erk1/2 phosphorylation is diminished in the kidneys from Tubule-FGFR2 ${ }^{-/-}$mice after cisplatin injection. a Representative micrographs showing the immunohistochemical staining images for $\mathrm{p}$-Erk1/2 at day 1 after cisplatin injection. b Western blot analysis showing the induction of Erk1/2 phosphorylation in the kidneys from Tubule-FGFR2 ${ }^{-/-}$or control littermates at different time points after cisplatin injection. c Graph showing the semiquantita-

cells with recombinant FGF2 protein for different times. As shown in Figure $8 \mathrm{a}$ and b, Erk1/2 phosphorylation was increased at $15 \mathrm{~min}$ and peaked at $4 \mathrm{~h}$ after FGF2 treatment. PD98059, a specific MEK1 inhibitor, abolished FGF2-stimulated Erk1/2 phosphorylation. We then tested whether Erk1/2 signaling mediated the protective effect of FGF2 on cisplatin-induced cell death. As shown in Figure $8 \mathrm{c}$ and $\mathrm{d}$, immunostaining for anti-cleaved caspase 3 showed that cisplatin could significantly induce tubular cell apoptosis. FGF2 at $10 \mathrm{ng} / \mathrm{mL}$ remarkably inhibited cisplatin-induced caspase 3 cleavage and cell apoptosis. In addition, PD98059 could partly abolish the pro-survival effect of FGF2. These results suggest that FGF2 promotes tubular cell survival partly through stimulating Erk1/2 signaling. tive result for $p$-Erk1/2. ${ }^{*} p<0.05$ vs. control littermates, $n=3-4$. d Western blot assay for the p-Bad at day 1 after cisplatin injection. e Graph showing the semiquantitative result for $\mathrm{p}$-Bad in the kidneys from Tubule-FGFR $2^{-l-}$ and control littermates. ${ }^{*} p<0.05$ vs. control littermates, $n=4$. The number indicates the individual animal.

\section{Discussion}

We report here that numerous FGF family proteins were expressed in kidneys with ischemic/reperfusion or cisplatin-induced AKI, and specific ablation of FGFR2 from tubular cells rendered the mice susceptible to AKI and tubular cell apoptosis. In cultured kidney tubular cells, FGF2 could activate Erk1/2 signaling and inhibit cisplatin-induced cell death, whereas inhibiting this signaling could partially antagonize FGF2-inhibited cell death.

FGFs are a group of growth factors which are involved in development, cell proliferation, differentiation, cell survival, as well as angiogenesis [18]. Members of the FGF family proteins are indispensable for kidney development and maturation [26]. We found in this study that numer- 


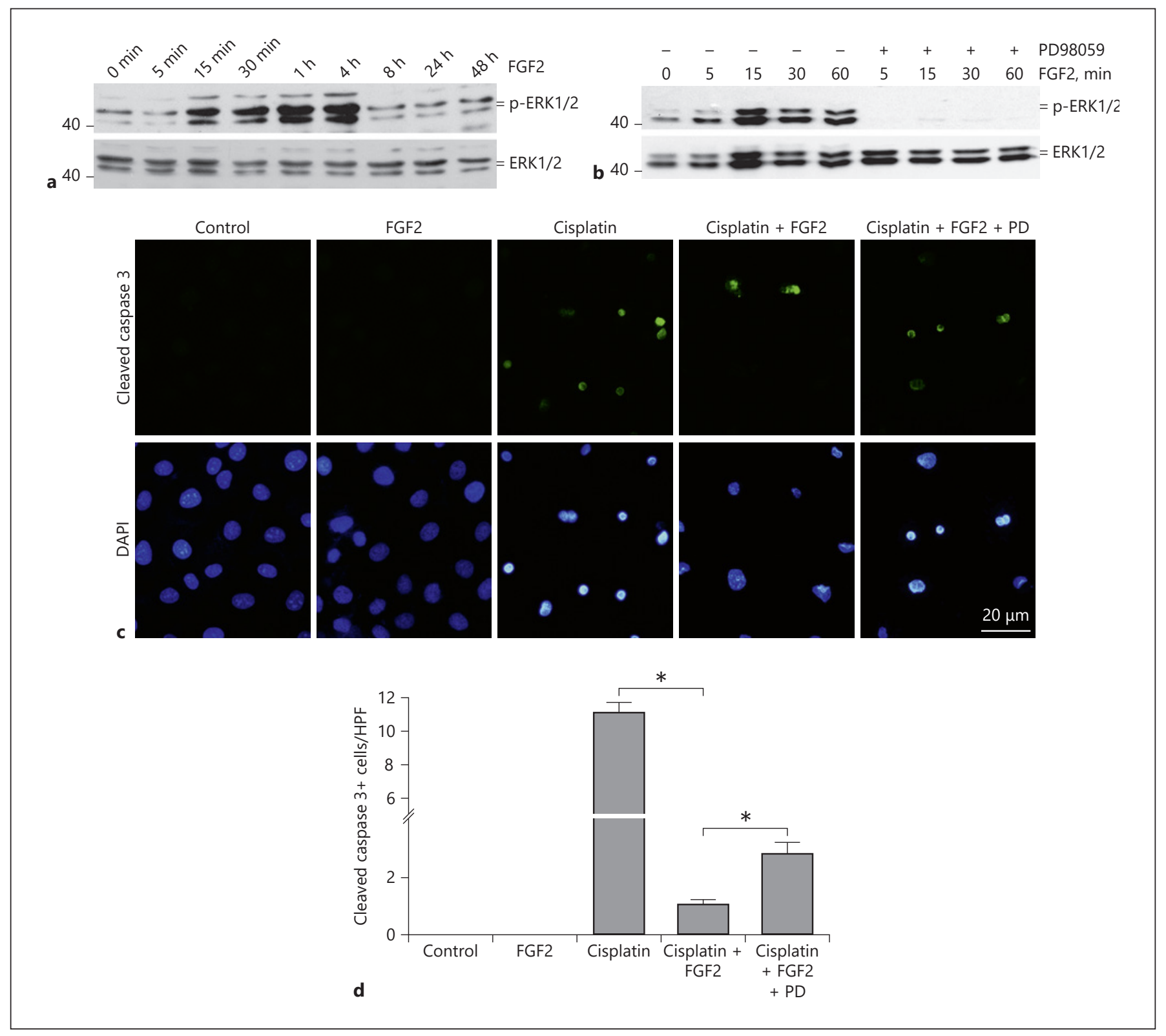

Fig. 8. FGF2 protects against cisplatin-induced cell apoptosis via the Erk1/2 pathway in NRK-52E cells. a Western blot results showing the induction of $\mathrm{p}$-Erk1/2 in a time-dependent manner. NRK$52 \mathrm{E}$ cells were treated with FGF2 $(10 \mathrm{ng} / \mathrm{mL})$ for various duration as indicated. b Mek1 inhibitor (PD98059, $10 \mu \mathrm{M}$ ) effectively blocked FGF2-induced Erk-1, 2 signaling activation. c Representative immunofluorescent staining images for cleaved caspase 3 showing that FGF2 protein could prevent cisplatin-induced apop- tosis in NRK-52E cells. NRK-52E cells were treated with cisplatin $(25 \mu \mathrm{g} / \mathrm{mL})$ for $12 \mathrm{~h}$ in the absence or presence of FGF2. Blockade of Erk1/2 signaling with PD98059 partly diminished the protective effect of FGF2 on cisplatin-induced cell apoptosis. Coverslips were counterstained with DAPI for nuclear visualization. d Quantitative determination of cleaved caspase 3-positive cells among groups as indicated. Data are presented as the percentage of the cells. ${ }^{*} p<0.05, n=4$. ous FGF family members, such as FGF2, FGF7, FGF 10, FGF12, FGF13, FGF18, and FGF22 were upregulated in IR-induced AKI, indicating that these FGFs may play a role in AKI. Among of them, FGF2, 7, and 10 bind with the receptor FGFR2. Thus, in this study, mice with a deletion of tubular cell FGFR2 were used to investigate the role of those FGFs in AKI. It has been reported that FGFR2 signaling affects growth and maturation of the 
metanephric mesenchyme (MM) and UB. Loss of FGFR2 in the MM leads to many kidney and urinary tract anomalies, while deletion of FGFR2 from the UB results in severe ureteric branching and mesenchymal defects $[13,21$, $22,27]$. Here, we crossbred mice expressing Cre driven by kidney-specific protein promoter with FGFR2-floxed mice. About one-third of them developed mild hydronephrosis at 2 months after birth, suggesting FGFR2 plays an important role in the development of the tubule system in the mammals. However, during the observation period, no obvious phenotypic change in the body weight or serum creatinine level was found in the knockouts compared to the control littermates.

In an AKI model, kidney tubular cells are susceptible to various injuries including ischemia and toxin, and tubular cell death is tightly related to the decline of the renal function. It has been reported that necrosis and apoptosis are the main forms of cell death in AKI [28-31]. In our study, we found that ablation of FGFR2 from tubular cells aggravated the IR or cisplatin-induced acute kidney dysfunction and tubular injury. Meanwhile, the number of apoptotic cells in the tubules was greater in knockouts, suggesting that the protective effect of FGF/FGFR2 against AKI may be through inhibiting tubular cell apoptosis.

The Erk1/2 signaling pathway mediates renal cell response to a diverse range of stimuli, and is involved in the pathogenesis of acute and chronic kidney injury [32-34]. As reported, in IR-induced AKI, the abundance of phosphorylated Erk1/2 increases by activating an EGFR/Ras/ Raf signaling cascade in tubular cells, and the blockade of Erk1/2 signaling deteriorates cell injury after IR [35, 36]. In a rat model of progressive membranous nephropathy, inhibiting Erk1/2 worsened DNA damage in podocytes and upregulated p21 expression [37]. In this study, FGF2 was able to protect NRK-52E cells against cisplatin-induced apoptotic cell death. This protective effect of FGF2 is partly mediated by the Erk1/2 signaling pathway, as blockade of Erk1/2 with PD 98059 could partly abolish the effect of FGF2 on the inhibition of caspase 3 . These results are consistent with the in vivo data that the Erk1/2 phosphorylation is inhibited in Tubule-FGFR2 ${ }^{-/-}$mice at day 1 after cisplatin injection. However, on the second and third days after cisplatin injection, the abundance of phosphorylated Erk1/2 was comparable between TubuleFGFR2 $^{-/-}$and Tubule-FGFR ${ }^{+/+}$kidneys, which suggests that FGFR2 signaling may be dispensable for Erk1/2 signaling activation in kidneys at the late stage.

Previous studies showed that Erk1/2 signaling activation plays an antiapoptotic role in various cell types through regulating bcl-2 family members [38-40]. The phosphorylation of Bad, a member of this family, has been shown to maintain the integrity of the mitochondrial membrane and prevent caspase activation, thus inhibiting cell apoptosis [41, 42]. Since inhibiting Erk1/2 signaling could only partly reverse the protective effect of FGF2 on cisplatin-induced apoptosis, it is highly probable that other pathways such as PI3K/Akt signaling may contribute to the pro-survival effect of FGF2 on tubular cells $[9,28,43]$.

In this study, we found that more FGFs members were upregulated in the kidneys after IR than those in the cisplatin-induced AKI model. In parallel, greater tubular cellular proliferation and regeneration were found in kidneys after IR than in cisplatin-induced AKI [28, 44, 45]. It is possible that the upregulation of FGF members such as FGF7 in kidneys after IR may account for the increased tubular cell proliferation compared to the cisplatin-induced AKI model [46].

In summary, we demonstrated that FGF/FGFR2 plays an important role in promoting tubular cell survival in IR and cisplatin-induced AKI. Erk1/2 signaling pathway activation partly mediates the protective effect of FGF/ FGFR2.

\section{Statement of Ethics}

No human samples were used in this study. All animals were maintained in the Specific Pathogen-Free Animal Center of Nanjing Medical University according to the guidelines of the Institutional Animal Care and Use Committee at Nanjing Medical University. The animal experiments conform to internationally accepted standards and have been approved by the Institutional Animal Care and Use Committee at Nanjing Medical University.

\section{Disclosure Statement}

The authors have no conflicts of interest to declare.

\section{Funding Sources}

This work was supported by National Science Foundation of China Grants 81570611/H0503, 81770675/H0503 (Dai C.), and 81900615/0503 (Xu Z.).

\section{Author Contributions}

Xu Z., Zhu X. and Wang M. performed the experiments and wrote the manuscript. Lu Y. revised the manuscript. Dai C. designed, supervised, and revised the manuscript. 


\section{References}

1 Remuzzi G, Benigni A, Finkelstein FO, Grunfeld JP, Joly D, Katz I, et al. Kidney failure: aims for the next 10 years and barriers to success. Lancet. 2013 Jul;382(9889):353-62.

2 Leung KC, Tonelli M, James MT. Chronic kidney disease following acute kidney injuryrisk and outcomes. Nat Rev Nephrol. 2013 Feb;9(2):77-85

3 Rifkin DE, Coca SG, Kalantar-Zadeh K. Does AKI truly lead to CKD? J Am Soc Nephrol. 2012 Jun;23(6):979-84.

4 Bellomo R, Kellum JA, Ronco C. Acute kidney injury. Lancet. 2012 Aug;380(9843):756-66.

5 Ramesh G, Reeves WB. Inflammatory cytokines in acute renal failure. Kidney Int Suppl. 2004 Oct;66(91):S56-61.

6 Havasi A, Borkan SC. Apoptosis and acute kidney injury. Kidney Int. 2011 Jul;80(1):29-40.

7 Dai C, Yang J, Liu Y. Single injection of naked plasmid encoding hepatocyte growth factor prevents cell death and ameliorates acute renal failure in mice. J Am Soc Nephrol. 2002 Feb;13(2):411-22.

8 Bonegio R, Lieberthal W. Role of apoptosis in the pathogenesis of acute renal failure. Curr Opin Nephrol Hypertens. 2002 May;11(3): 301-8.

9 Li J, Xu Z, Jiang L, Mao J, Zeng Z, Fang L, et al. Rictor/mTORC2 protects against cisplatin-induced tubular cell death and acute kidney injury. Kidney Int. 2014 Jul;86(1):86-102.

10 Goetz R, Mohammadi M. Exploring mechanisms of FGF signalling through the lens of structural biology. Nat Rev Mol Cell Biol. 2013 Mar;14(3):166-80.

11 Ohuchi H, Hori Y, Yamasaki M, Harada H, Sekine K, Kato S, et al. FGF10 acts as a major ligand for FGF receptor 2 IIIb in mouse multiorgan development. Biochem Biophys Res Commun. 2000 Nov;277(3):643-9.

12 Qiao J, Uzzo R, Obara-Ishihara T, Degenstein L, Fuchs E, Herzlinger D. FGF-7 modulates ureteric bud growth and nephron number in the developing kidney. Development. 1999 Feb;126(3):547-54.

13 Bates CM. Role of fibroblast growth factor receptor signaling in kidney development. Pediatr Nephrol. 2011 Sep;26(9):1373-9.

14 Kriz W, Hähnel B, Rösener S, Elger M. Longterm treatment of rats with FGF-2 results in focal segmental glomerulosclerosis. Kidney Int. 1995 Nov;48(5):1435-50.

15 Strutz F. The role of FGF-2 in renal fibrogenesis. Front Biosci (Schol Ed). 2009 Jun;1(1):125-31.

16 Hoffman SB, Massaro AN, Soler-García AA, Perazzo S, Ray PE. A novel urinary biomarker profile to identify acute kidney injury (AKI) in critically ill neonates: a pilot study. Pediatr Nephrol. 2013 Nov;28(11):2179-88.

17 Kirov A, Duarte M, Guay J, Karolak M, Yan C, Oxburgh L, et al. Transgenic expression of nonclassically secreted FGF suppresses kidney repair. PLoS One. 2012;7(5):e36485.

18 Belov AA, Mohammadi M. Molecular mechanisms of fibroblast growth factor signaling in physiology and pathology. Cold Spring Harb Perspect Biol. 2013 Jun;5(6):5.

19 Sims-Lucas S, Cusack B, Baust J, Eswarakumar VP, Masatoshi H, Takeuchi A, et al. Fgfr1 and the IIIc isoform of Fgfr2 play critical roles in the metanephric mesenchyme mediating early inductive events in kidney development. Dev Dyn. 2011 Jan;240(1):240-9.

20 Yamaguchi TP, Harpal K, Henkemeyer M, Rossant J. fgfr-1 is required for embryonic growth and mesodermal patterning during mouse gastrulation. Genes Dev. 1994 Dec; 8(24):3032-44.

21 Hains D, Sims-Lucas S, Kish K, Saha M, McHugh K, Bates CM. Role of fibroblast growth factor receptor 2 in kidney mesenchyme. Pediatr Res. 2008 Dec;64(6):592-8.

22 Bates CM. Role of fibroblast growth factor receptor signaling in kidney development. Am J Physiol Renal Physiol. 2011 Aug;301(2): F245-51.

23 Sims-Lucas S, Di Giovanni V, Schaefer C, Cusack B, Eswarakumar VP, Bates CM. Ureteric morphogenesis requires Fgfr1 and Fgfr2/ Frs $2 \alpha$ signaling in the metanephric mesenchyme. J Am Soc Nephrol. 2012 Apr;23(4): 607-17.

24 Walker KA, Sims-Lucas S, Di Giovanni VE, Schaefer C, Sunseri WM, Novitskaya T, et al. Deletion of fibroblast growth factor receptor 2 from the peri-wolffian duct stroma leads to ureteric induction abnormalities and vesicoureteral reflux. PLoS One. 2013;8(2):e56062.

25 Shao X, Somlo S, Igarashi P. Epithelial-specific Cre/lox recombination in the developing kidney and genitourinary tract. J Am Soc Nephrol. 2002 Jul;13(7):1837-46.

26 Cancilla B, Ford-Perriss MD, Bertram JF. Expression and localization of fibroblast growth factors and fibroblast growth factor receptors in the developing rat kidney. Kidney Int. 1999 Dec;56(6):2025-39.

27 Zhao H, Kegg H, Grady S, Truong HT, Robinson ML, Baum M, et al. Role of fibroblast growth factor receptors 1 and 2 in the ureteric bud. Dev Biol. 2004 Dec;276(2):403-15.

28 Bonventre JV, Yang L. Cellular pathophysiology of ischemic acute kidney injury. J Clin Invest. 2011 Nov;121(11):4210-21.

29 Yang JR, Yao FH, Zhang JG, Ji ZY, Li KL, Zhan J, et al. Ischemia-reperfusion induces renal tubule pyroptosis via the CHOP-caspase-11 pathway. Am J Physiol Renal Physiol. 2014 Jan;306(1):F75-84.

30 Jiang M, Wei Q, Dong G, Komatsu M, Su Y, Dong Z. Autophagy in proximal tubules protects against acute kidney injury. Kidney Int. 2012 Dec;82(12):1271-83.

31 Livingston MJ, Dong Z. Autophagy in acute kidney injury. Semin Nephrol. 2014 Jan; 34(1):17-26.

32 Choi IJ, Kim SY, Kwon CH, Kim YK. Rosiglitazone inhibits proliferation of renal proximal tubular cells via down-regulation of ERK and Akt. Ren Fail. 2010 Jan;32(1):103-11.
33 Feliers D, Kasinath BS. Erk in kidney diseases. J Signal Transduct. 2011;2011:768512.

34 Wang S, Wei Q, Dong G, Dong Z. ERK-mediated suppression of cilia in cisplatin-induced tubular cell apoptosis and acute kidney injury. Biochim Biophys Acta. 2013 Oct; 1832(10):1582-90.

35 Chen J, Chen JK, Harris RC. Deletion of the epidermal growth factor receptor in renal proximal tubule epithelial cells delays recovery from acute kidney injury. Kidney Int. 2012 Jul;82(1):45-52.

36 Tang J, Liu N, Zhuang S. Role of epidermal growth factor receptor in acute and chronic kidney injury. Kidney Int. 2013 May;83(5):804-10.

37 Pippin JW, Durvasula R, Petermann A, Hiromura K, Couser WG, Shankland SJ. DNA damage is a novel response to sublytic complement C5b-9-induced injury in podocytes. J Clin Invest. 2003 Mar;111(6):877-85.

38 Arany I, Megyesi JK, Reusch JE, Safirstein RL. CREB mediates ERK-induced survival of mouse renal tubular cells after oxidant stress. Kidney Int. 2005 Oct;68(4):1573-82.

39 Iwasawa M, Miyazaki T, Nagase Y, Akiyama T, Kadono Y, Nakamura M, et al. The antiapoptotic protein $\mathrm{Bcl}-\mathrm{xL}$ negatively regulates the bone-resorbing activity of osteoclasts in mice. J Clin Invest. 2009 Oct;119(10):3149-59.

40 Luanpitpong S, Chanvorachote P, Stehlik C, Tse W, Callery PS, Wang L, et al. Regulation of apoptosis by Bcl-2 cysteine oxidation in human lung epithelial cells. Mol Biol Cell. 2013 Mar;24(6):858-69.

41 Schüller AC, Ahmed Z, Levitt JA, Suen KM, Suhling K, Ladbury JE. Indirect recruitment of the signalling adaptor Shc to the fibroblast growth factor receptor 2 (FGFR2). Biochem J. 2008 Dec;416(2):189-99.

42 Kim JH, Lee SS, Jung MH, Yeo HD, Kim HJ, Yang JI, et al. N-acetylcysteine attenuates glycerol-induced acute kidney injury by regulating MAPKs and Bcl-2 family proteins. Nephrol Dial Transplant. 2010 May;25(5):1435-43.

43 Kusch A, Hoff U, Bubalo G, Zhu Y, Fechner M, Schmidt-Ullrich R, et al. Novel signalling mechanisms and targets in renal ischaemia and reperfusion injury. Acta Physiol (Oxf). 2013 May;208(1):25-40.

44 Basile DP, Friedrich JL, Spahic J, Knipe N, Mang H, Leonard EC, et al. Impaired endothelial proliferation and mesenchymal transition contribute to vascular rarefaction following acute kidney injury. Am J Physiol Renal Physiol. 2011 Mar;300(3):F721-33.

45 He S, Liu N, Bayliss G, Zhuang S. EGFR activity is required for renal tubular cell dedifferentiation and proliferation in a murine model of folic acid-induced acute kidney injury. Am J Physiol Renal Physiol. 2013 Feb;304(4):F356-66.

46 Ichimura T, Finch PW, Zhang G, Kan M, Stevens JL. Induction of FGF-7 after kidney damage: a possible paracrine mechanism for tubule repair. Am J Physiol. 1996 Nov;271(5 Pt 2):F967-76. 